\title{
Influence of Directional Solidification on the Mechanical Properties of Cu-Al-Be-Nb-Ni Alloy
}

\author{
Gabrielly de Lucena Tiburtino ${ }^{a}$, Rafael Tavares Vieira ${ }^{a}$, Ieverton Caiandre Andrade Brito ${ }^{b}$, Rafael \\ Evaristo Caluête ${ }^{c}$, Rodinei Medeiros Gomes ${ }^{c}$, Danniel Ferreira de Oliveira ${ }^{a, b} *$ (-) \\ ${ }^{a}$ Programa de Pós-Graduação em Ciência e Engenharia de Materiais, Universidade Federal da \\ Paraíba, João Pessoa, PB, Brasil \\ ${ }^{b}$ Departamento de Engenharia de Materiais, Universidade Federal da Paraiba, João Pessoa, PB, Brasil \\ ${ }^{c}$ Departamento de Engenharia Mecânica, Universidade Federal da Paraíba, João Pessoa, PB, Brasil
}

Received: February 15, 2019; Revised: May 01, 2019; Accepted: July 14, 2019

\begin{abstract}
Copper-based polycrystalline shape memory alloys (SMAs) have limitations for many practical applications due to their low superelasticity and low ductility. In order to overcome this situation, in recent years, the production of copper-based SMAs by directional solidification process has attracted the interest of many researches. In this sense, the present work had as objective to evaluate, through instrumented indentation tests, the influence of the solidification direction on the elastic modulus, hardness and superelasticity of a $\mathrm{Cu}-\mathrm{Al}-\mathrm{Be}-\mathrm{Nb}-\mathrm{Ni}$ alloy produced by directional solidification. The results showed that the superelasticity, remnant depth, elastic modulus and hardness DHV-1 are strongly dependent on the direction of application of the load in relation to the solidification direction, that is, the alloy presented an anisotropic behavior for its mechanical properties.
\end{abstract}

Keywords: Remnant depth, directional solidification, anisotropic behavior.

\section{Introduction}

The practical applications of shape memory alloys (SMAs) are dependent on the characteristics inherent to the martensitic transformation, such as: phase transformation temperatures, shape memory extension, and superelasticity'. Among the various SMAs, Ni-Ti based alloys stand out, in many practical applications, because they have excellent shape memory and superelasticity characteristics. However, due to the high processing cost of these alloys, copperbased shape memory alloys have emerged as a promising alternative material for various applications, such as high damping material, sensors and actuators ${ }^{2}$.

However, the copper-based SMAs produced by conventional casting are quite fragile. This fragility is related to its large elastic anisotropy and the strong dependence of the transformation deformation with the orientation ${ }^{3}$. To circumvent these limitations, copper-based alloys are modified with by additions of grain refiners to improve the ductility of these alloys. In particular, $\mathrm{Nb}$-modified $\mathrm{Cu}$-Al-Be alloys have significantly improved properties ${ }^{4,5}$. Moreover, grain refinement can improve to a certain extent the ductility and fatigue strength of shape memory alloys ${ }^{6}$.

In recent years, the production of copper-based SMAs via directional solidification process has attracted the interest of many researches ${ }^{3,6,7,8,9}$. The development of a columnar grain structure via directional solidification promotes a reduction of the number of grain boundaries and can exclude the triple junctions completely ${ }^{7}$. Around these triple junctions of grain boundaries the stress concentration (induced by the martensitic transformation) is high and the stress induced martensitic transformation occurs in a partially and with the formation of several variants of martensite ${ }^{10}$. The elimination of triple junctions significantly improves the mechanical properties, however, alloys with columnar grains produced by directional solidification have a strongly anisotropic structure, with a straight morphology and parallel to the solidification direction ${ }^{11}$.

Liu et. al. ${ }^{11}$ investigated the characteristics of the superelastic anisotropy of a $\mathrm{Cu}-\mathrm{Al}-\mathrm{Mn}$ alloy produced by directional solidification, through tensile tests, and reported that superelasticity decreased from $9.8 \%\left(0^{\circ}\right.$ - angle between TD and $\mathrm{SD})$ to $2.7 \%\left(60^{\circ}\right.$ - angle between TD and SD), then increased to $8.4 \%\left(90^{\circ}\right.$ - angle between $\mathrm{TD}$ and $\left.\mathrm{SD}\right)$, thus presenting a large anisotropy with increase the angle between tensile direction (TD) and solidification direction (SD). The authors attributed this large anisotropy of superelasticity to the combined effects of grain orientation and grain boundaries, where the influence of grain boundaries had an obvious dependence on orientation.

There is a growing interest in applying the nanoindentation technique to evaluate the superelastic behavior of shape memory alloys ${ }^{12,13,14,15,16}$. This technique can be used to investigate small volumes of material and therefore can be used to study local variations in mechanical response ${ }^{13}$. The mechanical behavior of $\mathrm{Cu}$-Al-Be polycrystalline alloys was investigated by Montecinos et al. ${ }^{17}$ via instrumented indentation using a Berkovich-type indenter and estimated 
the elastic modulus and hardness from the depth-load curves using the Oliver-Pharr method.

The influence of the indenter type on the mechanical properties of SMAs was investigated by some researchers ${ }^{12,13,14,18}$. According to Grummon et. al. ${ }^{18}$, regardless of the maximum depth applied, indents made with pyramidal indenters (Vickers and Berkovitch) recover only about a third of the indent profile, representing an indication that localized strains near the surface are high enough to inhibit recovery.

In this sense, the present work had as objective to evaluate, through instrumented indentation tests, the influence of the solidification direction in the elastic modulus, hardness and superelasticity of a $\mathrm{Cu}-\mathrm{Al}-\mathrm{Be}-\mathrm{Nb}-\mathrm{Ni}$ alloy produced by directional solidification.

\section{Experimental Procedure}

The alloy $\mathrm{Cu}-11.8 \mathrm{Al}-0.58 \mathrm{Be}-0.5 \mathrm{Nb}-0.27 \mathrm{Ni}$ was initially melted in an electric resistance furnace and in the sequence the material was cast in an upward vertical unidirectional cooling furnace. To achieve directional solidification the pre-cast metal is cast in a cylindrical mold (with refractory ceramic mold and steel base 1045) preheated at $1000{ }^{\circ} \mathrm{C}$. After the pouring, a water pump was driven to cool the mold base and direct the heat extraction stream. The fluid used to cool the mold base was a water-ice mixture at a temperature of approximately $15^{\circ} \mathrm{C}$.
After solidification, the alloy was homogenized at $850{ }^{\circ} \mathrm{C}$ for $12 \mathrm{~h}$ and then samples were prepared in four different planes $\left(0^{\circ} \mathrm{SD}, 30^{\circ} \mathrm{SD}, 60^{\circ} \mathrm{SD}\right.$ and $\left.90^{\circ} \mathrm{SD}\right)$ to the solidification direction (SD), with dimensions of $15 \mathrm{~mm} \times 10 \mathrm{~mm} \times 4$ $\mathrm{mm}$. The specimens were heated at $850^{\circ} \mathrm{C}$ for $1 \mathrm{~h}$ and then quenched in water at $25^{\circ} \mathrm{C}$. After the tempering treatment, the specimens were submitted to ultrahigh-hardness loadingunloading in a DUH-211S Shimadzu ultramicrodurometer in order to obtain the hardness and elastic modulus values as a function of the load applied through a computer coupled to the machine and DUH software. Indentations were performed randomly along the surface of the sample and the parameters used in the assay were as follows:

Type of indenter: Vickers (pyramidal tip);

Applied load: $250 \mathrm{mN}$;

Load application time: $10 \mathrm{~s}$;

Load application speed: $13.32 \mathrm{mN} / \mathrm{s}$.

The martensitic transformation temperatures were investigated by differential scanning calorimetry using a Shimadzu DSC-60; the samples were heated and cooled at a rate of $10^{\circ} \mathrm{C} / \mathrm{min}$. The microstructure of the tempered specimens was investigated by optical microscopy.

\section{Results and Discussion}

The optical micrographs for four different samples $\left(0^{\circ} \mathrm{SD}, 30^{\circ} \mathrm{SD}, 60^{\circ} \mathrm{SD}\right.$ and $\left.90^{\circ} \mathrm{SD}\right)$ are shown in Fig. 1.

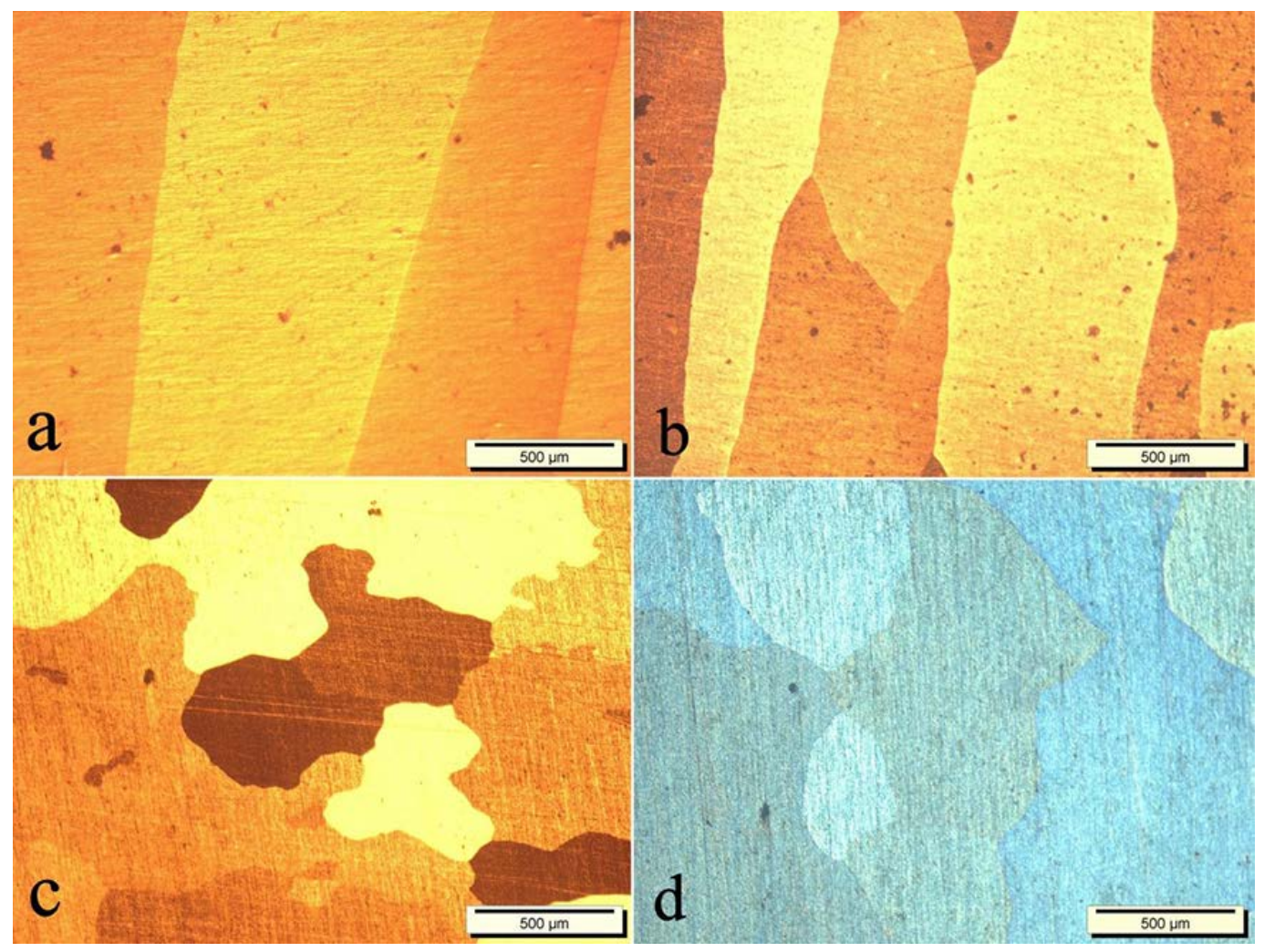

Figure 1. Microstructure as a function of solidification direction: (a) $0^{\circ} \mathrm{SD}$, (b) $30^{\circ} \mathrm{SD}$, (c) $60^{\circ} \mathrm{SD}$, (d) $90^{\circ} \mathrm{SD}$. 
It can be seen in Fig. 1a that the microstructural morphology of the $0^{\circ} \mathrm{SD}$ direction presented grains that grew straight, along the direction of heat extraction, and contours of straight longitudinal grains. The alloy presented the austenite phase for all the specimens. The presence of triple junctions is already evident from the direction $30^{\circ} \mathrm{SD}$.

In Figure 2 and Table 1 are shown the phase transformation temperatures of the alloy as a function of the solidification direction. It was observed that at room temperature the alloy is completely austenitic in all solidification directions, as verified by optical microscopy. It was also verified that the phase transformation temperatures presented a small variation with the solidifcation direction, showing a maximum difference around $9{ }^{\circ} \mathrm{C}$.

This difference is associated with changes in the mean grain size as a function of the solidification direction. The decrease in average grain size decreases the temperature $M_{s}{ }^{19,20}$. This reduction in Ms with decreasing grain size indicates that grain boundaries prevent the formation of self-accommodating martensite variants, requiring greater supercooling for transformation to occur ${ }^{19}$.
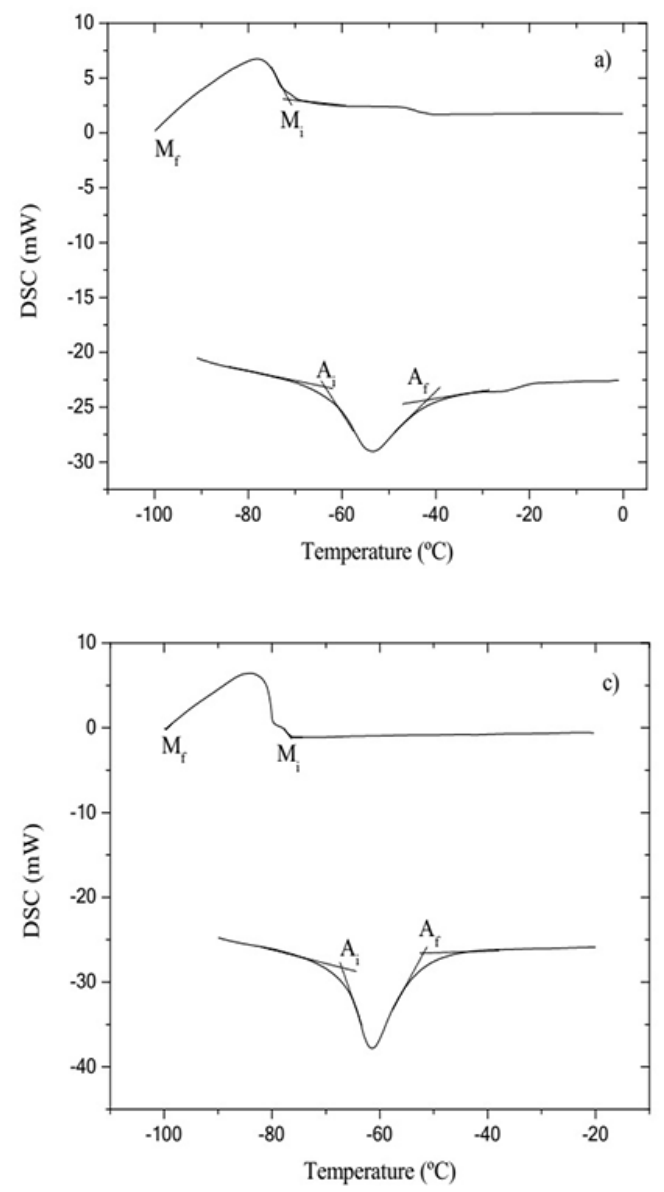

The influence of the solidification direction on the mechanical properties was evaluated through instrumented indentation tests for the following solidification directions: $0^{\circ} \mathrm{SD}, 30^{\circ} \mathrm{SD}, 60^{\circ} \mathrm{SD}$ and $90^{\circ} \mathrm{SD}$. The influence of the solidification direction on the elastic modulus, hardness, remnant depth and superelasticity was evaluated. To characterize the superelasticity (SE) was used to the ratio of remnant depth (RDR) proposed by Pfetzing et. al. ${ }^{21}$, defined by:

$$
R D R=\frac{h_{\text {rem }}}{h_{\max }}
$$

Where: $h_{\text {rem }}$ is the depth remnant and $h_{\max }$ the maximum depth. The superelasticity was calculated by the following relation:

$$
S E=1-R D R
$$

Figure 3 shows a typical indentation depth-load curve, where the parameters related to the depth of penetration are highlighted. It is possible to observe that, for the solidification direction $0^{\circ} \mathrm{SD}$, the deep penetration maximum
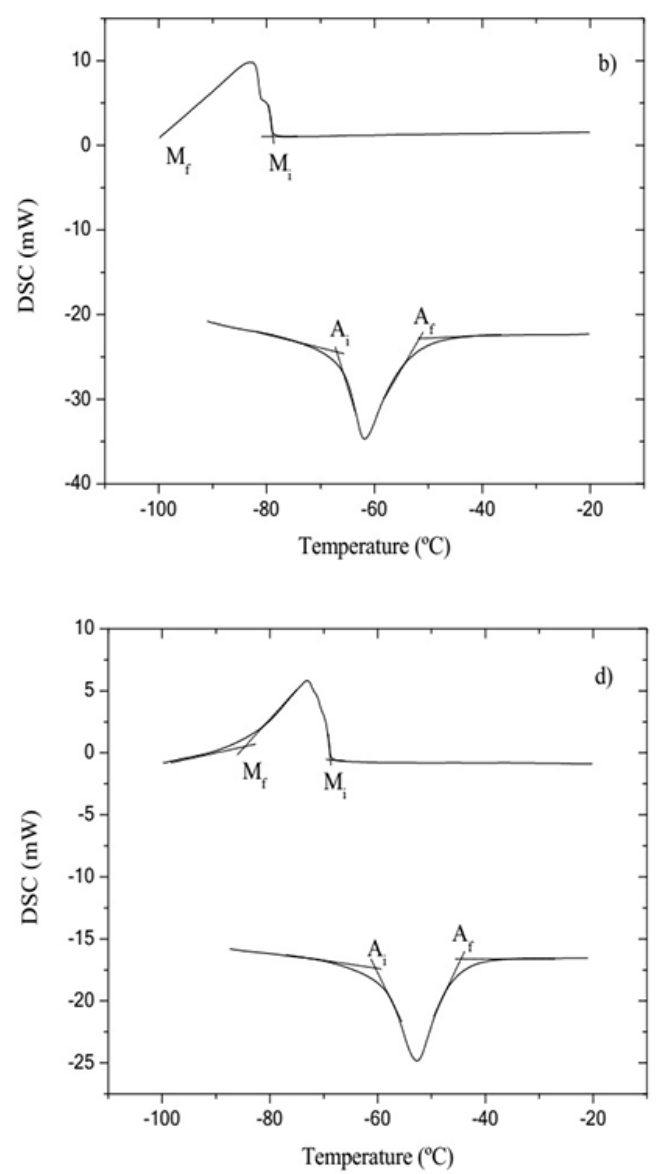

Figure 2. DSC - phase transformation temperatures as a function of the solidification direction: (a) $0^{\circ} \mathrm{SD}$, (b) $30^{\circ} \mathrm{SD}$, (c) $60^{\circ} \mathrm{SD}$, (d) $90^{\circ} \mathrm{SD}$. 
Table 1. Temperatures of phase transformations as a function of solidification direction.

\begin{tabular}{lcccc}
\hline $\begin{array}{l}\text { Solidification } \\
\text { direction }\end{array}$ & $\mathrm{M}_{\mathrm{s}}\left({ }^{\circ} \mathrm{C}\right)$ & $\mathrm{M}_{\mathrm{f}}\left({ }^{\circ} \mathrm{C}\right)$ & $\mathrm{A}_{\mathrm{s}}\left({ }^{\circ} \mathrm{C}\right)$ & $\mathrm{A}_{\mathrm{f}}\left({ }^{\circ} \mathrm{C}\right)$ \\
\hline $0^{\circ} \mathrm{SD}$ & -70 & -98 & -65 & -42 \\
$30^{\circ} \mathrm{SD}$ & -78 & -98 & -68 & -50 \\
$60^{\circ} \mathrm{SD}$ & -75 & -98 & -67 & -50 \\
$90^{\circ} \mathrm{SD}$ & -70 & -89 & -60 & -42 \\
\hline
\end{tabular}

for the maximum applied load of $250 \mathrm{mN}$ was $1.97 \mu \mathrm{m}$ and the remnant depth after the release of the load was $1.39 \mu \mathrm{m}$. This remnant depth value representing an RDR of approximately 0.71 indicates that after removal from the load the pseudoelastic recovery was approximately $29 \%$ relative to the maximum depth applied. According to Pfetzing et. al. ${ }^{14}$ RDR values less than 0.1 are expected for perfect pseudoelastic recovery.

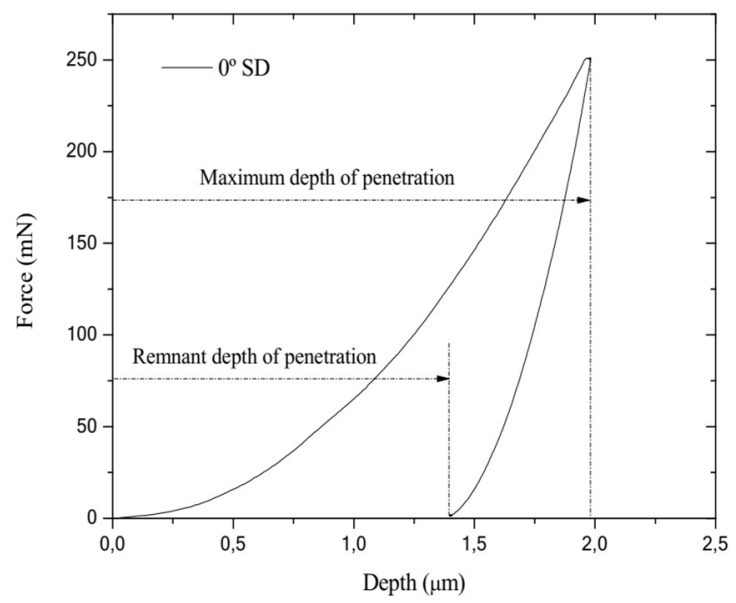

Figure 3. Typical indentation depth-load curve.

The influence of the solidification direction on elastic modulus is shown in Fig. 4. It was observed that for angles located between $0^{\circ} \mathrm{SD}$ and $60^{\circ} \mathrm{SD}$, the elastic modulus shows an increasing tendency proportionally to $\mathrm{SD}$, reaching a value average maximum of $85 \mathrm{GPa}$ for direction $60^{\circ} \mathrm{SD}$. With increasing direction, after $60^{\circ} \mathrm{SD}$, the elastic modulus gradually decreases reaching an average value of 82.5 $\mathrm{GPa}$ for $90^{\circ} \mathrm{SD}$. Similar behavior for elastic modulus was verified by Liu et. al. ${ }^{11}$ for a $\mathrm{Cu}-\mathrm{Al}-\mathrm{Mn}$ alloy obtained via directional solidification, and subjected to tensile tests as a function of the solidification direction. Montecinos et. al. ${ }^{17}$ find a mean value of $74 \mathrm{GPa}$ for the elastic modulus of the austenite phase $(\beta)$ of a polycrystalline $\mathrm{Cu}-\mathrm{Al}-\mathrm{Be}$ alloy by means of instrumented indentation tests with a maximum applied load of $2000 \mu \mathrm{N}$.

The anisotropy of the elastic modulus, as a function of the solidification direction, can be attributed to a change

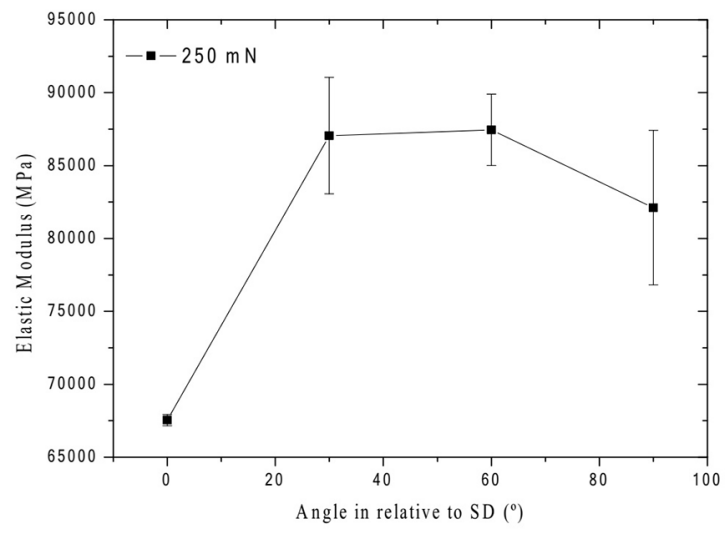

Figure 4. Elastic modulus as a function of solidification direction.

in the crystallographic orientation with the variation of the angle in relation to $0^{\circ} \mathrm{SD}$.

As observed by Liu et. al. ${ }^{11}$ the sample CG- $0^{\circ}$ along the tensile direction has a strong texture oriented in the $<001>$ direction, while the CG- $90^{\circ}$ sample has a double orientation texture between $<001>$ and $<110>$, in the tensile direction.

Figure 5 shows the influence of the solidification direction on the DHV-1 hardness. It is verified that the hardness DHV-1 presented behavior similar to the elastic modulus, however the maximum value of the hardness DHV-1 is reached in $30^{\circ} \mathrm{SD}$. After the $30^{\circ} \mathrm{SD}$, a gradual decrease of the values presented by the DHV-1 hardness occurs.

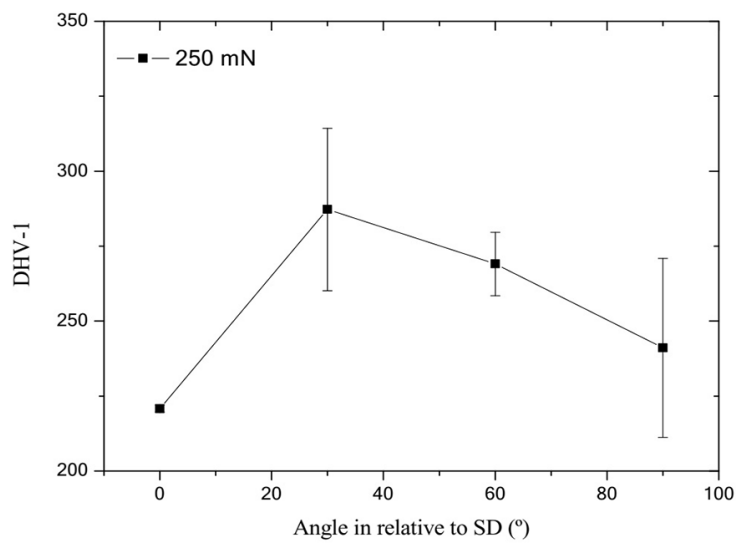

Figure 5. DHV-1 hardness as a function of solidification direction.

Mahtabi et. al. ${ }^{22}$ investigated a relationship between the microhardness and the martensite induction stress in superelastic NiTi alloys. A linear relationship between the loading transformation stress and the microhardness was observed. According to the authors for samples with higher induction stress under a constant load, a smaller amount of material will be pushed into the fully martensitic region, resulting in a lower permanent deformation and therefore a higher Vickers hardness value. 
Figure 6 shows the influence of the solidification direction on the remnant depth. It is observed that for angles located between $0^{\circ} \mathrm{SD}$ and $30^{\circ} \mathrm{SD}$, a gradual decrease of the remnant depth occurs. Between the $30^{\circ} \mathrm{SD}$ and $60^{\circ} \mathrm{SD}$ the remnant depth shows a slight increase. Already between the $60^{\circ}$ $\mathrm{SD}$ and $90^{\circ} \mathrm{SD}$, the remnant depth shows a significantly increasing trend, reaching a maximum value for $90^{\circ} \mathrm{SD}$, where the maximum value is $2 \mu \mathrm{m}$.

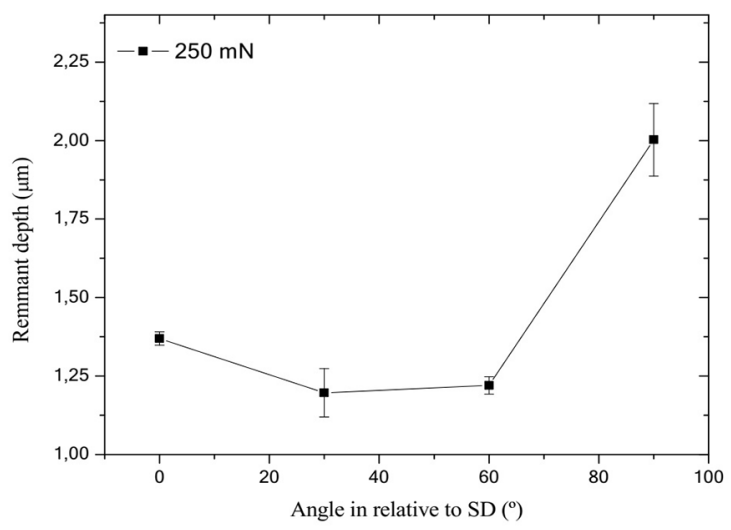

Figure 6. Remnant depth as a function of solidification direction.

The remnant depth can be attributed to plastic deformation and/or retained martensite, since pyramidal tip indenters cause high deformations and high gradients below the tip that cannot be accommodated only by martensitic phase transformation but require additional plastic deformation ${ }^{14}$. Thus, any martensite that forms during loading will occur irreversibly, since the high dislocation density will both fix and assist in the stabilization of martensitic variants, limiting its reversion to the mother phase, in the removal of the applied load ${ }^{13}$.

It is important to note that the mechanisms of deformation of the austenite phase vary in relation to the tip of the pyramidal indenter. According to Dar and Chen ${ }^{23}$ the material slightly below the surface in contact with the tip is subjected to high concentration of tension due to the small area of contact and plastically deform.

Already the part of material a little more distant of the tip undergoes sufficiently high stresses to undergo martensitic transformation, but below the yield strength point of the austenite. While part of the still further material exhibits relatively low stresses, elastically deforming and recovering the elastic strain when the load is removed.

The influence of the solidification direction on the superelastic behavior by calculating the SE values from the obtained RDR values is shown in Fig. 7. It is observed that the superelasticity increases smoothly between the $0^{\circ} \mathrm{SD}$ and the $60^{\circ} \mathrm{SD}$, reaching a maximum value for $60^{\circ} \mathrm{SD}$. After the $60^{\circ} \mathrm{SD}$, there is a significant decrease in the superelastic values, presenting the lowest value for $90^{\circ} \mathrm{SD}$. The dependence of the superelasticity with the solidification direction was attributed by Liu et. al. ${ }^{11}$ to the combined effects of grain orientation and grain boundaries.

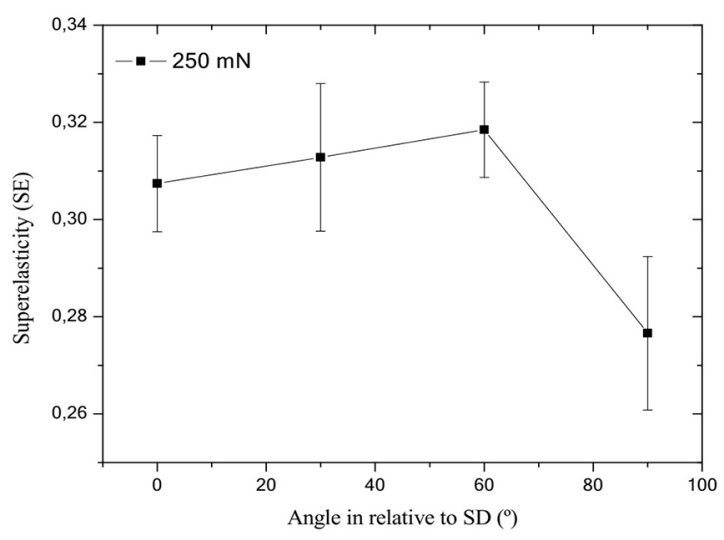

Figure 7. Superelasticity as a function of solidification direction.

The influence of the solidification direction on the superelasticity of an alloy with memory of ferromagnetic form $\mathrm{NiFeGaCo}$, realized by Huang et. al. ${ }^{24}$ showed that samples from the $0^{\circ}$ direction presented a pseudoelastic recovery superior to those obtained by the samples with directions of $45^{\circ}$ and $90^{\circ}$. This partially pseudoelastic recovery presented by the $45^{\circ}$ and $90^{\circ}$ is attributed to the incompatibility of the deformation across the grain boundaries when compression stress is applied to samples with these directions, presenting an amount of excessive plastic deformation in the crystalline defects, especially in the triple junctions.

The anisotropy presented for superelasticity, as a function of the solidification direction, can be attributed to a change in the crystallographic orientation. The crystallographic orientations that promote the martensitic transformation and suppress the plastic deformation usually exhibit a smaller dissipation of plastic energy, greater recovery of deformation and a greater hardness ${ }^{23}$.

\section{Conclusions}

The $\mathrm{Cu}-\mathrm{Al}-\mathrm{Be}-\mathrm{Nb}-\mathrm{Ni}$ alloy presented an anisotropic behavior for its mechanical properties as a function of the solidification direction. The results showed that superelasticity, remnant depth, elastic modulus and hardness DHV-1 are strongly dependent on the direction of application of the load in relation to the solidification direction. It was verified that the superelasticity increases for angles between the application of the load and the solidification direction varying in the interval $0^{\circ}-60^{\circ} \mathrm{SD}$ and decreases when the angle varies between $60^{\circ}-90^{\circ} \mathrm{SD}$, being the smaller value of superelasticity obtained for $90^{\circ} \mathrm{SD}$. 
The remnant depth presented a behavior contrary to that presented by superelasticity. The behavior of the elastic modulus in relation to the solidification direction is similar to that presented by superelasticity, the smallest value of the elastic modulus obtained by direction $0^{\circ} \mathrm{SD}$. The hardness DHV-1 increased at angles between the application of the load and the solidification direction varying in the interval $0^{\circ}-30^{\circ} \mathrm{SD}$ and decreases when the angle varies between $30^{\circ}-90^{\circ} \mathrm{SD}$.

\section{Acknowledgments}

This work was financially supported by the Brazilian National Council for Scientific and Technological Development$\mathrm{CNPq}$ and the Coordination for the Improvement of Higher Education Personnel-CAPES.

\section{References}

1. Sathish S, Mallik US, Raju TN. Microstructure and Shape Memory Effect of Cu-Zn-Ni Shape Memory Alloys. Journal of Minerals and Materials Characterization and Engineering. 2014;2(2):71-77.

2. Agrawal A, Dube KK. Methods of fabricating Cu-Al-Ni shape memory alloys. Journal of Alloys and Compounds. 2018;750:235-247.

3. Liu JL, Chen ZH, Huang HY, Xie JX. Microstructure and superelasticity control by rolling and heat treatment in columnargrained $\mathrm{Cu}-\mathrm{Al}-\mathrm{Mn}$ shape memory alloy. Materials Science and Engineering: A. 2017;696:315-322.

4. de Oliveira DF, de Lima SJG, Brito ICA, Gomes RM, Melo TAA. Mechanical Strength Evaluation of a CuAlBe Shape Memory Alloy under Different Thermal Conditions. Materials Science Forum. 2010;643:105-112.

5. de Albuquerque VHC, Melo TAA, de Oliveira DF, Gomes RM, Tavares JMRS. Evaluation of grain refiners influence on the mechanical properties in a CuAlBe shape memory alloy by ultrasonic and mechanical tensile testing. Materials \& Design. 2010;31(7):3275-3281.

6. Liu JL, Huang HY, Xie JX. The roles of grain orientation and grain boundary characteristics in the enhanced superelasticity of $\mathrm{Cu}_{71.8} \mathrm{Al}_{17.8} \mathrm{Mn}_{10.4}$ shape memory alloys. Materials \& Design. 2014;64:427-433.

7. Yuan B, Zheng P, Gao Y, Zhu M, Dunand DC. Effect of directional solidification and porosity upon the superelasticity of $\mathrm{Cu}-\mathrm{Al}-\mathrm{Ni}$ shape-memory alloys. Materials \& Design. 2015;80:28-35.

8. Fu HD, Xu S, Zhao H, Dong HB, Xie JX. Cyclic stress-strain response of directionally solidified polycrystalline $\mathrm{Cu}-\mathrm{Al}-\mathrm{Ni}$ shape memory alloys. Journal of Alloys and Compounds. 2017;714:154-159.

9. Yao PS, Huang HY, Su YJ, Xie JX. Two-Way Shape Memory Effect Induced by Tensile Deformation in Columnar-Grained $\mathrm{Cu}_{717} \mathrm{Al}_{18.1} \mathrm{Mn}_{10.2}$ Alloy. Materials (Basel). 2018;11(11). pii: E2109.
10. Ueland SM, Schuh CA. Grain boundary and triple junction constraints during martensitic transformation in shape memory alloys. Journal of Applied Physics. 2013;114(5):053503.

11. Liu JL, Huang HY, Xie JX. Superelastic anisotropy characteristics of columnar-grained $\mathrm{Cu}-\mathrm{Al}-\mathrm{Mn}$ shape memory alloys and its potential applications. Materials \& Design. 2015;85:211-220.

12. Ni W, Cheng YT, Grummon DS. Microscopic shape memory and superelastic effects under complex loading conditions. Surface and Coatings Technology. 2004;177-178:512-517.

13. Muir Wood AJ, Clyne TW. Measurement and modelling of the nanoindentation response of shape memory alloys. Acta Materialia. 2006;54(20):5607-5615.

14. Pfetzing-Micklich J, Wagner MFX, Zarnetta R, Frenzel J, Eggeler G, Markaki AE, et al. Nanoindentation of a Pseudoelastic NiTiFe Shape Memory Alloy. Advanced Engineering Materials. 2010;12(1-2):13-19.

15. San Juan J, Nó ML, Schuh CA. Superelastic cycling of CuAl-Ni shape memory alloy micropillars. Acta Materialia. 2012;60(10):4093-4106.

16. Maletta C, Furgiuele F, Sgambitterra E, Callisti M, Mellor BG, Wood RJK. Indentation response of a NiTi shape memory alloy: modeling and experiments. Frattura ed Integrità Strutturale. 2012;21:5-12.

17. Montecinos S, Cuniberti A, Simison S. Instrumented indentation of transforming and no-transforming phases in $\mathrm{Cu}-\mathrm{Al}-\mathrm{Be}$ shapememory alloys. Intermetallics. 2012;28:58-64.

18. Grummon DS, Ni W, Cheng YT. Exploiting Shape Memory and Superelasticity in Engineered Surfaces. In: SMST-2003 Proceedings of the International Conference on Shape Memory and Superelastic Technologies; 2003 May 5-8; Pacific Grove, CA, USA. p. 661-672.

19. Montecinos S, Cuniberti A. Martensitic Transformation and Grain Size in a Cu-Al-Be alloy. Procedia Materials Science. 2012;1:149-155

20. Ko WS, Maisel SB, Grabowski B, Jeon JB, Neugebauer J. Atomic scale processes of phase transformations in nanocrystalline NiTi shape-memory alloys. Acta Materialia. 2017;123:90-101.

21. Pfetzing J, Schaefer C, Somsen A, Wagner MFX. Nanoindentation of pseudoelastic NiTi shape memory alloys: Thermomechanical and microstructural aspects. International Journal of Materials Research. 2009;100(7):936-942.

22. Mahtabi MJ, Yadollahi A, Rahmati M, Stone TW. Correlation Between Hardness and Loading Transformation Stress of Superelastic NiTi. Arabian Journal for Science and Engineering. 2018;43(9):5029-5033.

23. Dar RD, Chen Y. Nanoindentation studies of small-scale martensitic transformations and ductile precipitate effects in dual-phase polycrystalline shape memory alloys. Acta Materialia. 2015;91:112-127.

24. Huang YJ, Liu J, Hu QD, Liu QH, Karaman I, Li JG. Applications of the directional solidification in magnetic shape memory alloys. IOP Conference Series: Materials Science and Engineering. 2016;117:012029. 